\title{
Phylogenetic Analysis of Alloiococcus otitis gen. nov., sp. nov., an Organism from Human Middle Ear Fluid
}

\author{
M. AGUIRRE AND M. D. COLLINS* \\ Department of Microbiology, AFRC Institute of Food Research, Reading Laboratory, \\ Shinfield, Reading RG2 9AT, United Kingdom
}

\begin{abstract}
The partial 16S rRNA sequence of an unknown bacterium that was originally isolated from middle ear fluids of children with persistent otitis media was determined by reverse transcription. A comparison of this sequence with sequences from other gram-positive species having low guanine-plus-cytosine contents revealed that this bacterium represents a new line of descent, for which the name Alloiococcus otitis gen. nov., sp. nov., is proposed. The type strain is strain NCFB 2890.
\end{abstract}

Faden and Dryja (7) recently reported the isolation of an unknown organism from typanocentesis fluid collected from middle ears of young children who were suffering from chronic otitis media. The cells of this bacterium were large gram-positive cocci (often present as diplococci or tetrads) which phenotypically most closely resembled aerococci and streptococci (7). However, the organism differed from aerococci and streptococci in being catalase positive. Despite possessing catalase, the bacterium could not be identified by using the Staph-Ident system (Analytab Products), and its taxonomic position remained unresolved (7).

$16 \mathrm{~S}$ rRNA sequence analysis has assumed a central role in ascertaining the phylogenetic relationships of bacteria (17).

\section{MATERIALS AND METHODS}

Cultures and biochemical tests. Strains $3621,4491,7213$, and $7760^{\mathrm{T}}$ ( $\mathrm{T}=$ type strain) were received from $\mathrm{D}$. H. Batts and R. R. Hinshaw, Upjohn Laboratories, Kalamazoo, Mich. Cultures were grown on blood agar plates and ToddHewitt broth (Oxoid Ltd., Basingstoke, United Kingdom) supplemented with $5 \%$ horse serum at $37^{\circ} \mathrm{C}$. Biochemical tests were performed by using the API 20 STREP system (API-Biomerieux, Basingstoke, United Kingdom) according to the instructions of the manufacturer. Test preparations were incubated at $37^{\circ} \mathrm{C}$, and tests were read after 4 and $24 \mathrm{~h}$ and 7 days.

GAGUUUGAUCCUGGCUCAGGACGAACGCUGGCGGCAUGCCUAAUACAUGCAAGUCGAACGCCAAAUCUUCCUGCUUGCAGGAAGAGGCGGAGUGGCGAAC GGGUGAGUAACACGUGAGGAACUUGCCCAUAAGAGGGGGAUAACACCCGGAAACGGGUGCUAAUACCGCAUAAGUUUUCCCAGUGCAUGCUGGGAAAAUA AAAGGUGGCUCUNUACCGCUUAUGGAUANNUCGCGGCGCAUUAGCUAGUUGGUAGGGUANAGGCCUACCAAGGCCAUGAUGCGUAGCCGACUUGAGAGGG UGAUCGGCCACACUGGAACUGAGACACGGUCCAGACUCCUACGGGAGGCAGCAGUAGGGAAUCUUCCACAAUGGGUGCAAGCCUGAUGGAGCAAUGCCGC GUGAGUGAAGAAGGACUUCGGUUCGUAAAGCUCUGUUGUUGGGGAAGAACACGGAUAGGAGUCACUGCCUAUCCCUUGACGGUACCCAACCAGAAAGUCA CGGCUAACUACGUGCCAGCAGCCGCGGUAAUACGUAGGUGACAAGCGUUGUCCGGAUUUAUUGGGCGUAAAGCGAGCGCAGGCGGUCCGGUAAGUCUGAU GUGAAAGCCCACGGCUCAACCGUGGAACGGCAUUGGAAACUGGCGGACUUGAAUGUAGCAGAGGAAAGUGGAAUUCCAUGUGUAGCGGUGGAAUGCGUAG AUAUAUGGAGGAACACCAGUGGCGAAAGCGACUUUCUGGGCUAUGAUUGACGCUGAGGCUCGAAAGCGUGGGGAGCGAACAGGAUUAGAUACCCUGGUAG UCCACGCCGUAAACGAUGAGUGCUAAGUGUUGGAGGGUUUCCGCCCUUCAGUGCUGGAGUUAACGCAUUAAGCACUCCGCCUGGGGAUUACGACCGCAAG GUUGAAACUCAAAAGAAUUGACGGGGGACCGCACAAGCGGUGGAGCAUGUGGUUUAAUUCGAAGCAACGCGAAGAACCUUA CCAGCUCUUGACAUCUUCU GCUAGCUUCAGAGAUGAAGCGUUCCCUUCGGGGACAGAAUGACAGGUGGUGCAUGGUUGUCGUCAGCUCGUGUCGUGAGAUGUUGGGUUAAGUCCCGUAA CGAGCGCAACCCUUAUUGUUAGUUGCCAGCAUUGAGUUGGGCACUCUAGCAAGACUGCCGGUGAUAAACCGGAGGAAGGCGGGGAUGACGUCAAAUCAUC AUGCCCCUUAUGAGCUGGGCUACACACGUGCUACAAUGGAUGGUACAACGAGUGGCGAGACCGCGAGGUUUAGCUAAUCUCCCAAAGCCAUUCUCAGUUC GGAUUGCAGGCUGCAACUCGCCUGCAUGAAGUCGGAAUCGCUAGUAAUCGCGGAUCAGAAUGCCGCGGUGAAUUCGUUCCCGGGUCUUGUACACACCGCC CGUCACACCACGAGAGUCUGAAACACCCGAAGCCGGCCGGGCAACCAUUUGGAGCCAGCCGUCGAA

FIG. 1. Primary structure of $16 \mathrm{~S}$ rRNA from Alloiococcus otitis. The first nucleotide and the last nucleotide in the sequence correspond to positions 9 and 1469 , respectively, of the $E$. coli numbering system (2).

In recent years this molecule has done much to clarify the inter- and intrageneric relationships of low-guanine-pluscytosine $(\mathrm{G}+\mathrm{C})$-content gram-positive cocci (viz., the genera Aerococcus, Enterococcus, Lactococcus, Leuconostoc, Pediococcus, and Streptococcus) (1, 3-5, 10, 12-16). Because of the possible role of the unknown coccus of Faden and Dryja in middle ear infections (7), we determined the partial 16S rRNA sequence of this organism in order to ascertain its precise phylogenetic position.

\footnotetext{
* Corresponding author.
}

DNA base composition. DNA was prepared as described by Garvie (9). DNA base composition was determined by subjecting the preparations to thermal denaturation in standard saline citrate as described by Garvie (9), using DNA from Escherichia coli NCDO 1984 as the standard.

Analysis of 16S rRNA. Cells were mechanically broken by using a Braun homogenizer, and rRNA was purified by using the procedure of Embley et al. (6). Nucleotide sequences were determined by the Sanger dideoxynucleotide chain termination method directly from rRNA by using avian myeloblastosis virus reverse transcriptase (6). The sequences generated were aligned, and homology values were determined by using the Beckman Microgenie program (11). Nucleotide substitution rates $\left(\mathrm{K}_{\mathrm{nuc}}\right.$ values) were calculated, and an unrooted phylogenetic tree was produced by using the algorithm of Fitch and Margoliash (8). 
TABLE 1. Homology values for a 1,340-nucleotide region of $16 \mathrm{~S}$ rRNAs of Alloiococcus otitis and other taxa

\begin{tabular}{|c|c|c|c|c|c|c|c|c|c|c|c|c|}
\hline \multirow[b]{2}{*}{ rRNA from: } & \multicolumn{12}{|c|}{$\%$ Homology with rRNA from: } \\
\hline & 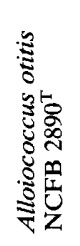 & 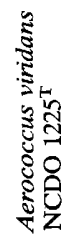 & 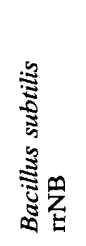 & 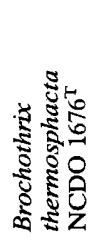 & 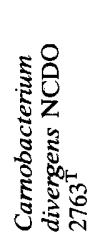 & 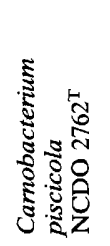 & 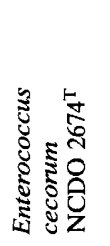 & 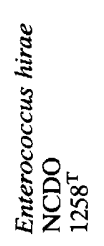 & 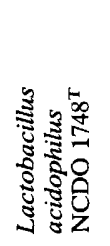 & 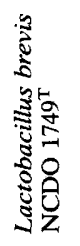 & 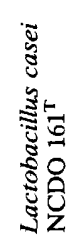 & 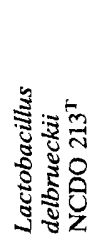 \\
\hline $\begin{array}{l}\text { Aerococcus viridans } \\
\text { NCDO } 1225^{\mathrm{T}}\end{array}$ & 88.7 & & & & & & & & & & & \\
\hline Bacillus subtilis rrNB & 87.8 & 87.6 & & & & & & & & & & \\
\hline $\begin{array}{l}\text { Brochothrix } \\
\text { thermosphacta NCDO } \\
1676^{\mathrm{T}}\end{array}$ & 85.7 & 89.0 & 89.4 & & & & & & & & & \\
\hline $\begin{array}{l}\text { Carnobacterium } \\
\text { divergens NCDO } \\
2763^{\mathrm{T}}\end{array}$ & 89.9 & 92.5 & 90.1 & 90.2 & & & & & & & & \\
\hline $\begin{array}{l}\text { Carnobacterium } \\
\text { piscicola NCDO } 2762^{\mathrm{T}}\end{array}$ & 89.5 & 91.9 & 90.5 & 90.7 & 97.5 & & & & & & & \\
\hline $\begin{array}{l}\text { Enterococcus ceconum } \\
\text { NCDO } 2674^{\mathrm{T}}\end{array}$ & 89.9 & 92.3 & 90.6 & 91.3 & 94.6 & 94.1 & & & & & & \\
\hline $\begin{array}{l}\text { Enterococcus hirae } \\
\text { NCDO } 1258^{\mathrm{T}}\end{array}$ & 89.1 & 91.6 & 90.3 & 91.7 & 94.8 & 94.6 & 97.0 & & & & & \\
\hline $\begin{array}{l}\text { Lactobacillus } \\
\text { acidophilus NCDO } \\
1748^{\mathrm{T}}\end{array}$ & 87.2 & 86.6 & 88.3 & 86.2 & 87.8 & 87.9 & 89.3 & 89.1 & & & & \\
\hline $\begin{array}{l}\text { Lactobacillus brevis } \\
\text { NCDO } 1749^{\mathrm{T}}\end{array}$ & 89.0 & 90.7 & 88.8 & 88.1 & 91.7 & 92.9 & 91.6 & 92.9 & 89.8 & & & \\
\hline $\begin{array}{l}\text { Lactobacillus casei } \\
\text { NCDO } 161^{\mathrm{T}}\end{array}$ & 88.9 & 90.0 & 88.5 & 88.5 & 91.9 & 92.0 & 90.7 & 91.1 & 89.7 & 93.5 & & \\
\hline $\begin{array}{l}\text { Lactobacillus delbrueckii } \\
\text { NCDO } 213^{\mathrm{T}}\end{array}$ & 86.5 & 87.7 & 87.2 & 85.7 & 87.2 & 87.2 & 88.9 & 89.3 & 94.3 & 90.0 & 89.7 & \\
\hline $\begin{array}{l}\text { Lactobacillus plantarum } \\
\quad \text { NCDO } 1752^{\mathrm{T}}\end{array}$ & 87.5 & 90.1 & 89.1 & 87.3 & 91.1 & 92.1 & 90.8 & 91.6 & 88.9 & 95.4 & 93.5 & 89.0 \\
\hline $\begin{array}{l}\text { Lactobacillus reuterii } \\
\text { NCDO } 2589^{\mathrm{T}}\end{array}$ & 88.6 & 89.9 & 87.7 & 87.3 & 90.5 & 90.4 & 90.6 & 91.0 & 91.5 & 93.1 & 93.6 & 91.2 \\
\hline $\begin{array}{l}\text { Lactococcus garvieae } \\
\text { NCDO } 2155^{\mathrm{T}}\end{array}$ & 85.0 & 88.4 & 86.1 & 86.7 & 87.7 & 88.1 & 90.6 & 89.4 & 85.1 & 88.1 & 87.3 & 87.1 \\
\hline 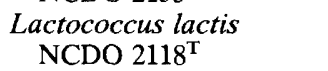 & 86.5 & 88.7 & 86.9 & 87.6 & 88.7 & 88.8 & 90.4 & 90.3 & 87.1 & 89.4 & 88.5 & 87.9 \\
\hline $\begin{array}{l}\text { Leuconostoc } \\
\text { mesenteroides NCDO } \\
523^{\mathrm{T}}\end{array}$ & 85.4 & 87.5 & 85.3 & 85.2 & 86.6 & 85.7 & 87.8 & 87.2 & 88.1 & 87.0 & 86.9 & 87.2 \\
\hline $\begin{array}{l}\text { Leuconostoc paramesen- } \\
\text { teroides } \mathrm{NCDO} 803^{\mathrm{T}}\end{array}$ & 85.9 & 89.3 & 86.8 & 87.9 & 90.1 & 89.9 & 90.7 & 90.7 & 87.8 & 90.4 & 90.4 & 87.5 \\
\hline $\begin{array}{l}\text { Listeria innocua } \text { NCTC } \\
\qquad 11288^{\mathrm{T}}\end{array}$ & 87.8 & 90.2 & 91.8 & 93.1 & 92.0 & 91.9 & 92.2 & 92.0 & 87.0 & 88.3 & 88.4 & 86.9 \\
\hline $\begin{array}{l}\text { Pediococcus acidilactici } \\
\text { NCFB } 2767^{\mathrm{T}}\end{array}$ & 89.9 & 89.4 & 88.7 & 88.8 & 92.1 & 92.0 & 92.1 & 92.4 & 89.5 & 94.6 & 93.8 & 86.9 \\
\hline $\begin{array}{l}\text { Pediococcus damnosus } \\
\quad \text { NCDO } 1832^{\mathrm{T}}\end{array}$ & 89.0 & 89.9 & 89.6 & 88.1 & 91.8 & 92.0 & 91.3 & 91.6 & 89.9 & 94.6 & 94.9 & 89.5 \\
\hline $\begin{array}{l}\text { Staphylococcus xylosus } \\
\text { NCTC } 11043^{\mathrm{T}}\end{array}$ & 86.7 & 90.6 & 91.6 & 89.8 & 89.8 & 89.6 & 90.2 & 90.5 & 85.8 & 87.2 & 87.5 & 86.1 \\
\hline $\begin{array}{l}\text { Streptococcus sanguis } \\
\text { NCTC } 7863^{\mathrm{T}}\end{array}$ & 86.9 & 89.4 & 89.7 & 88.2 & 89.6 & 89.9 & 91.1 & 91.2 & 86.5 & 88.8 & 88.9 & 86.7 \\
\hline $\begin{array}{l}\text { Streptococcus } \\
\text { parauberis NCDO } 651\end{array}$ & 86.7 & 88.9 & 87.0 & 87.8 & 89.3 & 90.0 & 90.6 & 90.9 & 86.5 & 88.6 & 88.4 & 86.2 \\
\hline $\begin{array}{l}\text { Streptococcus porcinus } \\
\text { NCDO } 600\end{array}$ & 86.2 & 88.6 & 86.9 & 87.8 & 89.0 & 89.7 & 90.4 & 90.4 & 87.0 & 87.8 & 88.3 & 86.6 \\
\hline $\begin{array}{l}\text { Streptococcus pyogenes } \\
\text { NCDO } 2381^{\mathrm{T}}\end{array}$ & 86.6 & 88.7 & 86.6 & 87.8 & 89.3 & 89.6 & 90.4 & 90.4 & 87.1 & 87.8 & 88.6 & 86.5 \\
\hline $\begin{array}{l}\text { Tetragenococcus } \\
\text { halophilus NCDO } \\
1635^{\mathrm{T}}\end{array}$ & 89.2 & 90.8 & 91.2 & 90.0 & 92.4 & 93.1 & 93.5 & 93.4 & 88.4 & 89.9 & 90.1 & 88.4 \\
\hline $\begin{array}{l}\text { Vagococcus fluvialis } \\
\text { NCDO } 2497^{\mathrm{T}}\end{array}$ & 88.9 & 92.7 & 89.5 & 91.2 & 93.7 & 93.2 & 94.3 & 94.3 & 88.3 & 91.3 & 90.0 & 88.3 \\
\hline $\begin{array}{l}\text { Vagococcus } \\
\text { salmoninarum NCFB } \\
2777^{\mathrm{T}}\end{array}$ & 88.5 & 91.7 & 90.0 & 90.1 & 94.4 & 93.9 & 94.1 & 94.6 & 87.0 & 90.2 & 90.5 & 86.9 \\
\hline
\end{tabular}


TABLE 1-Continued

$\%$ Homology with rRNA from:

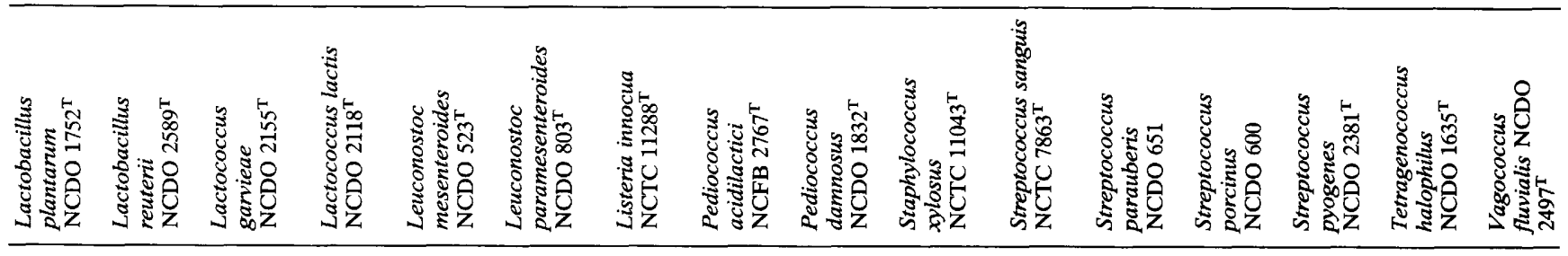

92.7

$87.5 \quad 88.0$

$88.5 \quad 87.9 \quad 95.0$

$82.2 \quad 88.5 \quad 85.6 \quad 85.7$

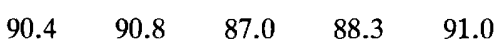

$\begin{array}{llllll}88.6 & 87.9 & 86.9 & 87.8 & 86.1 & 88.1\end{array}$

$\begin{array}{lllllll}94.3 & 94.2 & 88.9 & 89.0 & 86.6 & 90.2 & 89.7\end{array}$

$\begin{array}{llllllll}94.6 & 93.7 & 88.0 & 89.6 & 87.1 & 89.6 & 89.0 & 96.6\end{array}$

$\begin{array}{lllllllll}87.1 & 85.9 & 84.8 & 85.0 & 84.9 & 86.9 & 90.4 & 88.3 & 88.1\end{array}$

$\begin{array}{llllllllll}88.4 & 89.4 & 90.8 & 92.0 & 87.8 & 89.2 & 88.4 & 89.4 & 89.3 & 86.9\end{array}$

$\begin{array}{lllllllllll}87.6 & 88.2 & 91.6 & 92.5 & 86.8 & 88.4 & 87.4 & 88.0 & 88.4 & 85.7 & 96.7\end{array}$

$\begin{array}{llllllllllll}87.5 & 88.0 & 91.8 & 92.5 & 86.4 & 87.8 & 87.5 & 87.5 & 88.1 & 85.9 & 95.5 & 97.7\end{array}$

$\begin{array}{lllllllllllll}87.8 & 88.9 & 91.5 & 92.7 & 86.5 & 87.6 & 87.9 & 88.7 & 88.7 & 86.0 & 96.0 & 97.1 & 96.6\end{array}$

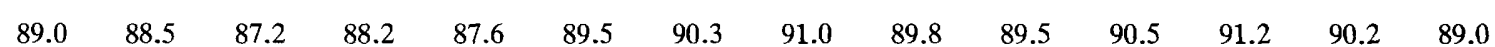

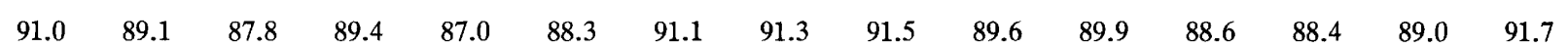

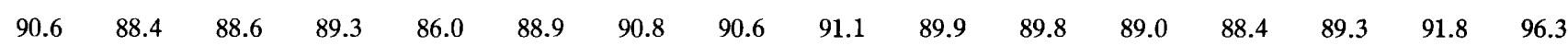




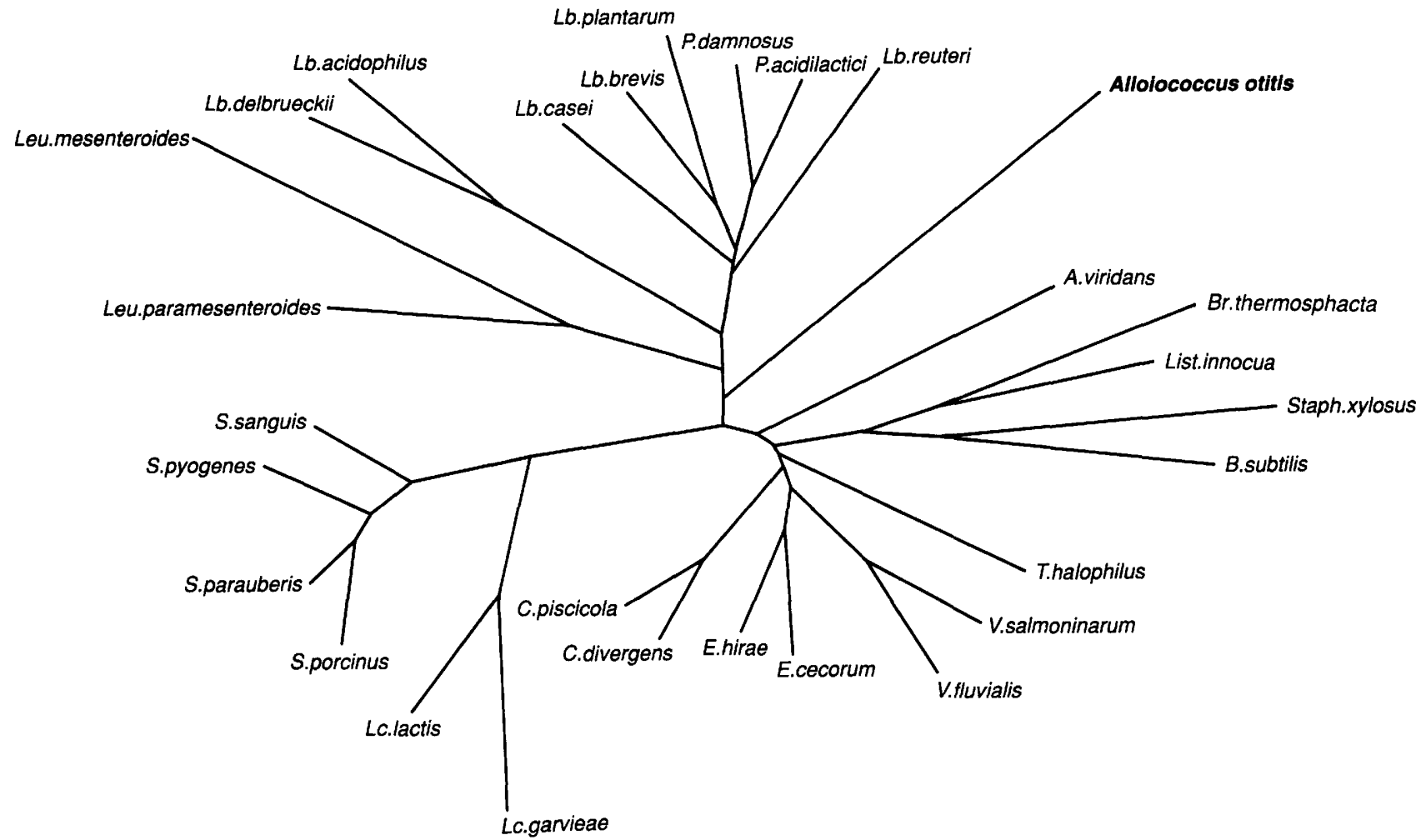

FIG. 2. Unrooted phylogenetic tree showing the position of Alloiococcus otitis within a group of gram-positive bacteria. The tree is based on a comparison of 1,340 bases. Lb., Lactobacillus; P., Pediococcus; Leu., Leuconostoc; S., Streptococcus; A., Aerococcus; Br., Brochothrix; List., Listeria; Staph., Staphylococcus; B., Bacillus; T., Tetragenococcus; C., Carnobacterium; E., Enterococcus; V., Vagococcus; Lc, Lactococcus.

Nucleotide sequence accession number. The partial $16 \mathrm{~S}$ rRNA sequence of strain $7760^{\mathrm{T}}$ has been deposited in the EMBL data base under accession number X59765.

\section{RESULTS AND DISCUSSION}

The four unknown strains formed pinpoint colonies which were off-white and alpha-hemolytic. Gram staining revealed that the cells were gram positive and were arranged in pairs, tetrads, and clumps. The strains were catalase positive and failed to produce acid from sugars. Pyrrolidonylarylamidase, $\beta$-galactosidase, and leucine arylamidase were produced. The estimated $\mathrm{G}+\mathrm{C}$ content was 44 to $45 \mathrm{~mol} \%$. These characteristics were in good agreement with the characteristics given in the description of Faden and Dryja (7).

The partial $16 \mathrm{~S}$ rRNA sequence of human strain $7760^{\mathrm{T}}$ is shown in Fig. 1. The reverse transcriptase sequence consisted of a continuous stretch of 1,466 bases representing approximately $96 \%$ of the total primary sequence. The first nucleotide and the last nucleotide in the sequence correspond to positions 9 and 1469 , respectively, of the $E$. coli $16 S$ rRNA sequence (2). The sequences of short fragments (ca. position 50 to position 450 , which included variable regions $\mathrm{V} 1$ and V2) of the $16 \mathrm{~S}$ rRNAs of the other isolates (strains 3621,4491 and 7213 ) were also determined and were found to be identical to the sequence of strain $7760^{\mathrm{T}}$, confirming the relatedness of the four human strains. In order to determine the phylogenetic position of the unknown bacterium, the sequence of strain $7760^{\mathrm{T}}$ was aligned and compared with the sequences of representative species belonging to the lowG+C-content genera Aerococcus, Bacillus, Brochothrix,
Carnobacterium, Enterococcus, Lactobacillus, Lactococcus, Leuconostoc, Listeria, Pediococcus, Staphylococcus, Streptococcus, and Vagococcus $(1,3-5,10,12-15)$. Percentages of similarity were calculated for a stretch of 1,340 nucleotides (ranging from position 107 to position 1433 of the $E$. coli sequence) (Table 1). The human strain exhibited relatively low levels of sequence relatedness with all of the reference species examined. The highest levels of homology were observed with aerococci, enterococci, carnobacteria, and pediococci (ca. 89 to $90 \%$ ). Significantly lower levels of homology were observed with lactococci, staphylococci, and streptococci (ca. 85 to $87 \%$ ). An unrooted tree constructed from derived $K_{\text {nuc }}$ values is shown in Fig. 2. The results of a distance matrix analysis confirmed the distinctiveness of the unknown bacterium. In this scheme the human strain formed a long, distinct line of descent, showing no specific relationship with any of the other low-G+Ccontent taxa examined (Fig. 2).

Faden and Dryja (7) believed that the unknown bacterium isolated from human patients with middle ear infections phenotypically more closely resembled Aerococcus viridans and streptococci than other gram-positive cocci (e.g., enterococci, micrococci, staphylococci). However, unlike aerococci and streptococci, the unknown bacterium was catalase positive. In our phylogenetic analysis we demonstrated that the unknown organism falls unambiguously within the low-G+C-content gram-positive bacteria. In addition, it is evident from the sequence data that the bacterium not only is genealogically distinct from aerococci and streptococci, but also exhibits no specific relationship with any of the other low-G+C-content genera examined. Be- 
cause of the phenotypic and phylogenetic distinctiveness of the unknown organism, we formally proposed that this bacterium should be classified in a new genus, Alloiococcus (Al.loi.o.coc'cus. Gr. adj. alloios, different; N.L. n. coccus, coccus; Alloiococcus, different coccus, referring to the phylogenetic distinctiveness of the organism), as Alloiococcus otitis (o.ti'tis. M.L. n. otitis, inflammation of the ear). The descriptions below are based on the results of Faden and Dryja (7) and our results.

Description of Alloiococcus gen. nov. Cells are ovoid and occur mostly in pairs or tetrads. Cells are gram positive and nonsporeforming. Grows at $45^{\circ} \mathrm{C}$, in the presence of $6.5 \%$ $\mathrm{NaCl}$, and on bile esculin agar. Aerobic. Catalase positive and oxidase negative. Acid is not produced from glucose and other sugars. Pyrrolidonylarylamidase positive. The DNA base composition is 44 to $45 \mathrm{~mol} \% \mathrm{G}+\mathrm{C}$. The type species is Alloiococcus otitis.

Description of Alloiococcus otitis sp. nov. Cells are ovoid and often occur as diplococci and tetrads. Grows slowly on solid media; after $48 \mathrm{~h}$ at $37^{\circ} \mathrm{C}$ small alpha-hemolytic colonies are produced on blood agar. Growth occurs in the presence of $6.5 \% \mathrm{NaCl}$ and on bile esculin agar. No growth occurs at $45^{\circ} \mathrm{C}$ or in an anaerobic environment. Acid is not produced from arabinose, dulcitol, glycerol, glucose, inulin, lactose, maltose, mannose, mannitol, raffinose, rhamnose, ribose, salicin, sucrose, sorbitol, trehalose, or xylose. Catalase positive and oxidase negative. Starch and esculin are not hydrolyzed; hippurate may or may not be hydrolyzed. Pyrrolidonylarylamidase, $\beta$-galactose, and leucine arylamidase are produced. Arginine dihydrolase is not produced. The DNA base composition is 44 to $45 \mathrm{~mol} \% \mathrm{G}+\mathrm{C}$. Isolated from middle ear fluids of children with persistent otitis media with effusion. The type strain is strain NCFB $2890(=7760)$.

\section{ACKNOWLEDGMENTS}

We are grateful to R. R. Hinshaw and D. H. Batts, The Upjohn Co., for the gift of cultures.

\section{REFERENCES}

1. Bentley, R. W., J. A. Leigh, and M. D. Collins. 1991. Intrageneric structure of Streptococcus based on comparative analysis of small-subunit rRNA sequences. Int. J. Syst. Bacteriol. 41: 489-494.

2. Brosius, J., M. L. Palmer, J. P. Kennedy, and H. F. Noller. 1978. Complete nucleotide sequence of a 16S ribosomal RNA gene from Escherichia coli. Proc. Natl. Acad. Sci. USA 75:48014805 .

3. Collins, M. D., C. Ash, J. A. E. Farrow, S. Wallbanks, and A. M. Williams. 1990. 16S ribosomal ribonucleic acid sequence analy- ses of lactococci and related taxa. Description of Vagococcus fluvialis gen. nov., sp. nov. J. Appl. Bacteriol. 67:453-460.

4. Collins, M. D., S. Wallbanks, D. J. Lane, J. Shah, R. Nietupski, J. Smida, M. Dorsch, and E. Stackebrandt. 1991. Phylogenetic analysis of the genus Listeria based on reverse transcriptase sequencing of 16S rRNA. Int. J. Syst. Bacteriol. 41:240-246.

5. Collins, M. D., A. M. Williams, and S. Wallbanks. 1990. The phylogeny of Aerococcus and Pediococcus as determined by 16S rRNA sequence analysis: description of Tetragenococcus gen.nov. FEMS Microbiol. Lett. 70:255-262.

6. Embley, T. M., J. Smida, and E. Stackebrandt. 1988. Reverse transcriptase sequencing of $16 \mathrm{~S}$ ribosomal RNA from Faenia rectivirgula, Pseudonocardia thermophila and Saccharopolyspora hirsuta, three wall IV actinomycetes which lack mycolic acids. J. Gen. Microbiol. 134:961-966.

7. Faden, H., and D. Dryja. 1989. Recovery of a unique bacterial organism in human middle ear fluid and its possible role in chronic otitis media. J. Clin. Microbiol. 27:2488-2491.

8. Fitch, W. M., and E. Margoliash. 1967. Construction of phylogenetic trees: a method based on mutation distances as estimated from cytochrome $\mathrm{c}$ sequences is of general applicability. Science 155:279-284.

9. Garvie, E. I. 1976. Hybridization between the deoxyribonucleic acids of some strains of heterofermentative lactic acid bacteria. Int. J. Syst. Bacteriol. 26:116-122.

10. Martinez-Murcia, A. J., and M. D. Collins. 1990. A phylogenetic analysis of the genus Leuconostoc based on reverse transcriptase sequencing of $16 \mathrm{~S}$ rRNA. FEMS Microbiol. Lett. 70:73-84.

11. Queen, C., and L. J. Korn. 1984. A comprehensive sequence analysis program for the IBM personal computer. Nucleic Acids Res. 12:581-599.

12. Wallbanks, S., A. J. Martinez-Murcia, J. L. Fryer, B. A Phillips, and M. D. Collins. 1990. 16S ribosomal ribonucleic acid sequence determination of members of the genus Carnobacterium and related lactic acid bacteria. Description of Vagococcus salmoninarum sp. nov. Int. J. Syst. Bacteriol. 40:224-230.

13. Whiley, R. A., H. Y. Fraser, C. W. I. Douglas, J. M. Hardie, A. M. Williams, and M. D. Collins. 1990. Streptococcus parasanguis sp. nov., an atypical viridans Streptococcus from human clinical specimens. FEMS Microbiol. Lett. 68:115-122.

14. Williams, A. M., and M. D. Collins. 1990. Molecular taxonomic studies on Streptococcus uberis types I and II. Description of Streptococcus parauberis sp. nov. J. Appl. Bacteriol. 68:485490.

15. Williams, A. M., J. A. E. Farrow, and M. D. Collins. 1989 Reverse transcriptase sequencing of $16 \mathrm{~S}$ ribosomal RNA from Streptococcus cecorum. Lett. Appl. Microbiol. 8:185-189.

16. Williams, A. M., U. M. Rodrigues, and M. D. Collins. 1991 Intrageneric relationships of enterococci as determined by reverse transcriptase sequencing of small-subunit rRNA. Res. Microbiol. 142:67-74.

17. Woese, C. R. 1987. Bacterial evolution. Microbiol. Rev. 51:221271. 